\title{
Household cost of out-patient treatment of Buruli ulcer in Ghana: a case study of Obom in Ga South Municipality
}

Hannah Brown Amoakoh ${ }^{1}$ and Moses Aikins 2* $^{*}$

\begin{abstract}
Background: The economic burden of diseases has become increasingly relevant to policy makers as healthcare expenditure keep rising in the face of limited and competing resources. Buruli ulcer (BU), a neglected but treatable tropical disease caused by Mycobacterium ulcerans, the only known environmental mycobacterium is capable of causing long term disability when left untreated. However, most BU studies have tended to focused on its bacteriology, epidemiology, entomology and other social determinants to the neglect of its economic evaluation. This paper reports estimated the household economic costs of BU and describe the intangible cost suffered by BU patients in an endemic area.
\end{abstract}

Methods: Retrospective one year cost data was used. A total of 63 confirmed BU cases were randomly sampled for the study. Economic cost and cost burden of BU were estimated. Sensitivity analysis was conducted to test the robustness of the cost estimates. Intangible cost measured stigmatization, pain, functional limitation and social isolation of children.

Results: The annual total household economic cost was US\$35,915.98, of which about $65 \%$ was cost incurred by children with a mean cost of US\$521.04. The mean annual household cost was US\$570.09. The direct cost was $96 \%$ of the total cost. Non-medical cost accounts for about $97 \%$ of the direct cost with a mean cost of US\$529.27. The mean medical cost was US\$18.94. The main cost drivers of the household costs were transportation (78\%) and food (12\%). Caregivers and adult patients lost a total of 535 productive days seeking care, which gives an indirect cost valued at US\$1,378.67 with a mean of US\$21.88. A total of 365 school days (about 1 year) were lost by $19 \mathrm{BU}$ patients (mean, 19.2 days). Functional loss and pain were low, and stigma rated moderate. Most children suffering from BU (84\%) were socially isolated.

Conclusion: Household cost burden of out-patient BU ulcer treatment was high. Household cost of BU is therefore essential in the design of its intervention. BU afflicted children experience social isolation.

Keywords: Buruli ulcer, Economic treatment cost, Cost burden, Social isolation, Ghana

\section{Background}

Buruli ulcer (BU), is a neglected infectious disease of tropical and subtropical climates caused by Mycobacterium ulcerans, the only known environmental mycobacterium and the third commonest mycobacterium after Mycobacterium tuberculosis and Leprosae. BU is capable of causing long term disability when left untreated but though

\footnotetext{
* Correspondence: mksaikins@ug.edu.gh

${ }^{2}$ Department of Health Policy, Planning \& Management, School of Public Health, College of Health Sciences, University of Ghana, P. O. Box LG13,

Legon, Accra, Ghana

Full list of author information is available at the end of the article
}

thoroughly researched, has limited studies that evaluate its economic burden [1-4]. The precise distribution and prevalence of $\mathrm{BU}$ is unknown, but it is reported annually in over 30 countries globally, the highest burden being in Sub-Saharan Africa $[4,5]$. BU can affect people of all ages but typically affects children less than 16 years and living in swampy, rural impoverished communities with limited access to healthcare $[3,4,6,7]$. Though the reservoir and mode of transmission of Mycobacterium ulcerans remains 
obscure, antecedent trauma has been implicated and living in a BU endemic area is the most important risk factor for acquiring BU [4,7-10]. Mycobacterium ulcerans secretes mycolactone a powerful toxin that causes massive cutaneous tissue destruction and immunosuppression [4,9]. BU presents as active disease of ulcerative or non-ulcerative forms, or as inactive disease characterized by a deep star shaped scar [4]. Recent use of rational antibiotic therapy has improved clinical outcomes of BU limiting surgery to large ulcers $[7,11,12]$.

Ghana, the second BU most endemic country in the world reports about 1,000 cases of BU annually $[4,13]$. Whilst knowledge about the aetiology of $\mathrm{BU}$ has improved in affected Ghanaian communities, there is still late reporting of the disease from fear of limb amputations, prolonged hospital stay, transportation and treatment costs at health facilities, loss of earnings and stigmatization of BU patients [1,14]. Poor implementation of free BU treatment services has led to inconsistent service provision. However, free BU services excludes transportation, feeding or accommodation costs of patients and their caregivers - a cost that has significant implications to household economies $[3,15,16]$. There is however, paucity of data on the cost and the burden of BU on affected households in Ghana as well as intangible costs borne by the patients. Though the indirect cost of BU was estimated at $\$ 550$ with 265 productive days lost among ulcerative cases of $\mathrm{BU}$ in previous Ghanaian studies, the total cost (direct and indirect) and the economic burden of BU to household is unknown $[6,17]$. The economic burden of diseases has become increasingly important as healthcare expenditure rapidly escalates whilst resources remain limited. This study was conducted to estimate the household economic costs of $\mathrm{BU}$ and describe the intangible cost suffered by BU patients in an endemic area.

\section{Methods}

\section{Study area}

The study was conducted in the Obom sub-district of the Ga South Municipality, Greater Accra Region, Ghana in May 2012. The first 5 districts nationwide with the highest prevalence of BU are: Amasie West (150.8/ 100,000), Asante Akim North (131.5/100,000), Upper Denkyira (114.7/100,000), Afigya Sekyere (107.1/100,000) and $\mathrm{Ga}(87.7 / 100,000)[1,2]$. Thus the study district is the fifth BU most endemic area in Ghana (i.e., prevalence of $87.7 / 100,000)$ and it has the highest burden of BU related deformity and disability. Obom has 362 communities with an estimated population of 210,727 and most adults are engaged mainly in small scae agricultural activities. The rural and swampy setting of Obom increases the risk of acquiring BU. The Obom Health Centre $(\mathrm{OHC})$, the main centre for BU treatment has no BU ward and therefore runs only an out-patient BU clinic. The OHC also runs Community based Health Planning and Services (CHPS) compounds that provide healthcare services in the communities. A non-governmental organization (NGO), "Stop Buruli Project" assists OHC by providing transport fare, breakfast and some logistics to the $\mathrm{OHC}$ and patients.

\section{Study design}

The study was a cross-sectional Cost-of-Illness study (COIs) from the household perspective. Economic costs were considered as shown in Figure 1. BU morbidity costs associated with treatment service were classified broadly into direct cost and disability costs [15]. The direct costs were further categorized as i) Medical costs included wound dressing supplies and other treatments (i.e., medications and other laboratory tests). ii) Nonmedical cost included transportation costs and feeding costs for patients and caregivers and miscellaneous costs. The

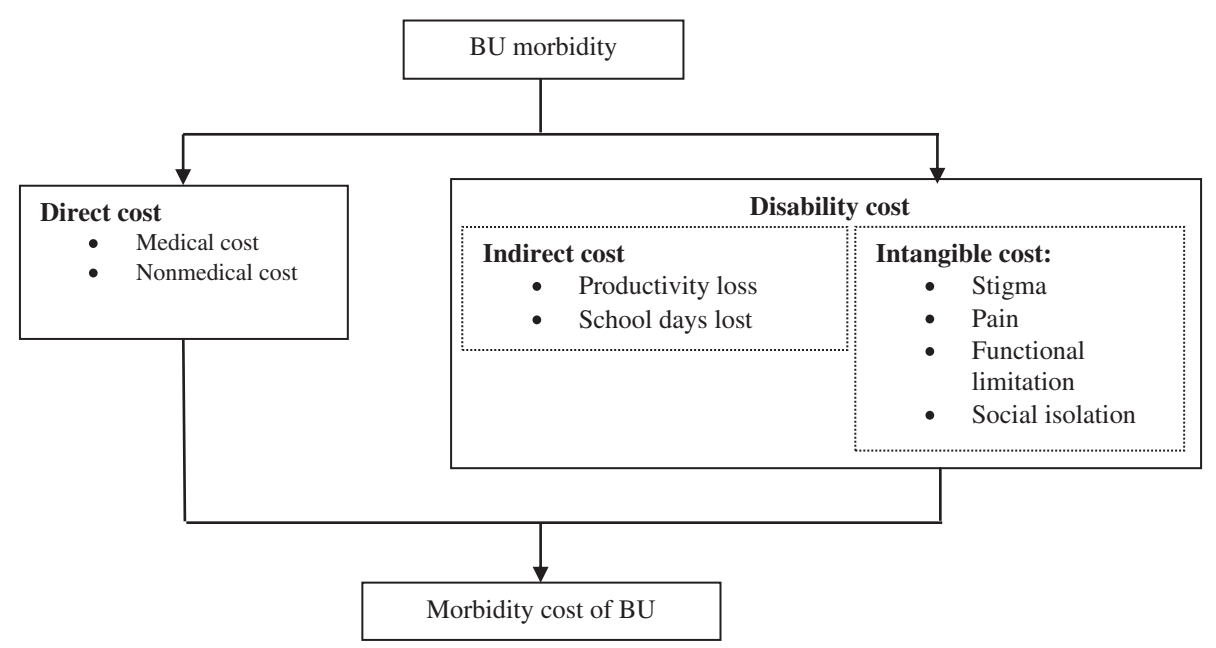

Figure 1 Conceptual framework of household BU morbidity costs. 
bottom-up approach of direct cost estimation was used [16]. The disability costs consisted of indirect costs and intangible costs. The indirect costs were productivity loss and school days lost by household members due to BU. Productivity losses were valued using the human capital approach [18-21] based on the actual local daily wage of working adults. Productivity losses of unemployed adults and children were not valued. Casual work was assumed for all working adults. Finally cost burden incurred by households were estimated. The local cost in Ghanaian currency (i.e., Ghana Cedis) was converted to their US dollar equivalents using the average exchange rate during the study period. Intangible costs were measured by describing the stigma, pain functional limitation and social isolation experienced by BU sufferers [14,15,22-24].

The number of school absenteeism days due to $\mathrm{BU}$ was operationally measured as non-attendance of a full school day session, and calculated as the summation of the number of school days lost by BU patients and their care givers of school going age, but was not valued in monetary terms as children below the age of 18 years in Ghana by law, are not employable.

\section{Study population and sample size}

Households with confirmed cases of $\mathrm{BU}$ at the $\mathrm{OHC}$ from $18^{\text {th }}$ May 2011 to $17^{\text {th }}$ May 2012 constituted the sample frame. An initial 105 confirmed cases was obtained from $\mathrm{OHC}$ database. However, 3 cases were confirmed dead and 3 others were conveniently sampled for pretesting the questionnaire bringing the final sampling frame to 99 confirmed cases. Using BU prevalence in the area as $87.7 / 100,000$ in 2002 [2] and a precision of $0.8 \%$ at $95 \%$ confidence interval, the sample size was calculated using the Cochran's formula [25]:

$n=\left(t^{2 *} p(1-p)\right) / d^{2}$, where $n$ is sample size, $t$ is 1.96 , $p$ is 0.000877 and $d$ is $0.8 \%$ - a sample size of 52.6 was obtained. The sample was further increase by a $20 \%$ non-response rate and/or recording errors, and rounded up to 63. Thus, a total of 63 confirmed BU cases and their households were randomly sampled for the study.

\section{Data collection}

Respondents were followed into their communities and a structured questionnaire was used to collect data on the patients' socio-demographic characteristics, household income, direct, indirect and intangible costs associated with seeking BU treatment services the last 12 months. Telephone interviews were used to clarify responses after initial data collection. The most reported intangible cost of BU are stigmatization, pain, functional limitation and social isolation [14,15,22-24]. Responses to queries on functional limitation and stigma were collected on a 5 point Likert scale [26]. Self reported felt stigma was studied using Vlassoff queries and modified for respondents who were children [24]. Data on functional limitation was collected using the Buruli Ulcer Functional Limitation Score Questionnaire (BUFLSQ). Functional limitation was defined as impairment in carrying out daily activities as a result of $\mathrm{BU}$ [22,23]. Daily activities listed in the BUFLSQ irrelevant to a BU patient (either because the patient is too young or old to perform the task), was recorded as not applicable. Self-reported ability to perform activities listed on the BUFLSQ was recorded without respondents being required to perform the tasks [22,23]. Self-reported perceived BU related pain was measured using a modified short MacGill pain questionnaire for children older than 11 years [27]. Social isolation was measured as the frequency a child is accompanied to the $\mathrm{OHC}$ by a caregiver during treatment and operationally defined as a child not being accompanied by a caregiver $50 \%$ of the time to the BU facility when seeking care as by culture, in Ghana, children are accompanied by caregivers when seeking medical care.

\section{Statistical and data analysis}

Data was entered in Microsoft Excel 2007 and STATA Version 10.0 was used for most of the analysis. The unit of analysis was BU affected households. The total household economic cost (i.e., medical, non-medical and indirect costs), productive days lost, mean costs and confidence intervals were estimated. Tables 1 and 2 provide details of the cost and productive lost estimations and valuation. The economic cost burden was estimated as a percentage of the household cost of UB treatment divided by the total household income. Sensitivity analysis was conducted to determine the robustness of cost estimation.

The main intangible costs measured were stigmatization, pain, functional limitation and social isolation. An overall mean for stigma, pain and functional limitation was computed as the mean of the means of each Likert scale item for children and adults separately. The Mann-Whitney test was used to compare Likert scale responses among male and female. A p-value $<0.05$ was considered significant for Mann-Whitney tests. Social isolation was calculated as the proportion of children who were not accompanied to the $\mathrm{OHC}$ during treatment.

The main assumptions made were: $i$ ) Costs estimated were incurred during the period, and were a consequence of $\mathrm{BU}$; ii) Household income prior to the onset of $\mathrm{BU}$ would have remained constant over the 12 months study period had BU not afflicted a household member; and iii) Children did not work and so did not incur productivity loss.

\section{Ethical review}

Ethical clearance for the study was obtained from the Ethical Review Committee, Research and Development Division of the Ghana Health Service, Ghana. Study 
Table 1 Household direct costs of treating BU, Ghana, 2012

\begin{tabular}{lll}
\hline Direct costs & Type of cost & Cost (US\$ per year) \\
\hline Medical & Wound dressing supplies & $\begin{array}{l}\text { Summation of the cost of all wound dressing supplies used during treatment } \\
\text { per month and normalized by sample size. }\end{array}$ \\
& Other treatments & $\begin{array}{l}\text { Summation of all out-of-pocket payments incurred on drugs and laboratory } \\
\text { tests by BU patients at OHC per month and normalized by sample size. }\end{array}$ \\
& Medical cost & Summation of total costs of wound dressing supplies and other treatments. \\
Non-medical & Transportation & Summation of the number of visits made by the BU patient and/or with caregiver \\
& to OHC per week multiplied by the return fare and normalized by sample size. \\
& Summation of the cost of food bought for the patient and/or caregivers during BU treatment \\
& Miscellaneous & $\begin{array}{l}\text { Summation of costs of phone calls made, cost of extra soap and disinfectants used for washing } \\
\text { of soiled clothing during BU treatment by all patients and normalized by sample size. } \\
\text { Nonmedical cost }\end{array}$ \\
& Summation of the total costs of transportation, food and miscellaneous. \\
& Summation of total medical and non-medical costs.
\end{tabular}

approval was also obtained from the Ga South Municipal Health Administration and the Obom Health Centre management. Identified respondent/caregiver was informed about the study. Respondent/caregiver was at liberty to withdraw from the study at will. Respondent/caregiver was assured of all information collected. Consented participant/caregiver was interviewed alone and in privacy. No compensations were paid to them. Written informed consent was obtained from all respondents.

\section{Results}

\section{Socio-demographic characteristics of the study population}

Table 3 shows that $52 \%$ of the BU cases were male and about $62 \%$ of BU cases were less than 15 years old with a median age of 13 years. Eighty-four percent of them reported being Christians. About $74 \%$ had primary school education of which $43 \%$ were male. Majority of respondents (75\%) were students/apprentices and 77\% lived in household size of 5 or more persons. Majority of respondents $(87 \%)$ had one lesion on their body with no difference between the sexes. All households studied had one household member suffering from BU except one household that had 2 BU sufferers. The mean and median duration of treatment was 3 months each.

\section{Total and mean household economic costs}

The annual total household economic cost was US $\$ 35,915.98$, of which about $65 \%$ was cost incurred by children with a mean cost of US\$521.04. The mean

Table 2 Household indirect costs of treating BU, Ghana, 2012

\begin{tabular}{|c|c|c|}
\hline Indirect costs & Time & Estimation approach \\
\hline \multirow[t]{3}{*}{ Travel time } & Patient & $\begin{array}{l}\text { Summation of the product of the number of visits by } \mathrm{BU} \text { patients to } \mathrm{OHC} \text { per week } \\
\text { by doubled travel time (i.e., to and fro } \mathrm{OHC} \text { ) and normalized by sample size. }\end{array}$ \\
\hline & Caregiver & $\begin{array}{l}\text { Summation of the product of the number of visits by caregivers to } \mathrm{OHC} \text { per week } \\
\text { by doubled travel time (i.e., to and fro } \mathrm{OHC} \text { ) and normalized by sample size. }\end{array}$ \\
\hline & Total travel time & Summation of patient and caregiver travel times. \\
\hline \multirow[t]{3}{*}{ Wound dressing time } & Patient & $\begin{array}{l}\text { Summation of the product of time spent on wound dressing (i.e., waiting and dressing) } \\
\text { by the number of wound dressing times per week by the number of weeks of wound } \\
\text { dressing and normalized by sample size. }\end{array}$ \\
\hline & Caregiver & $\begin{array}{l}\text { Summation of the product of the caregiver's waiting time spent on wound dressing by } \\
\text { the number of wound dressing times accompanied by caregiver per week by the number } \\
\text { of weeks of wound dressing accompanied by caregiver and normalized by sample size. }\end{array}$ \\
\hline & Total wound dressing time & Summation of patient and caregiver travel times. \\
\hline \multirow[t]{4}{*}{ Valuation } & Type of cost & Cost (US\$ per year) \\
\hline & Productivity lost by patient & $\begin{array}{l}\text { Summation of the product of the total number of workdays lost by adult BU patients in seeking } \\
\text { health care (i.e., travel and wound dressing times) by the average local daily wage rated. }\end{array}$ \\
\hline & Productivity lost by caregiver & $\begin{array}{l}\text { Summation of the product of the total number of workdays lost by caregivers in seeking health } \\
\text { care (i.e., travel and wound dressing times) by the average local daily wage rated. }\end{array}$ \\
\hline & $\begin{array}{l}\text { Total indirect cost } \\
\text { (i.e., productivity lost) }\end{array}$ & This is the summation of valued productive days lost by patient and caregiver. \\
\hline
\end{tabular}


Table 3 Socio-demographic characteristics of BU cases

\begin{tabular}{llll}
\hline Background characteristic & Male (\%) & Female (\%) & Total (\%) \\
\hline Age (years) & $23(37)$ & $16(25)$ & $39(62)$ \\
$<15$ & $10(16)$ & $14(22)$ & $24(38)$ \\
15 and over & & & \\
Religion & $27(43)$ & $26(41)$ & $53(84)$ \\
Christian & $6(2)$ & $4(7)$ & $10(17)$ \\
Other & \\
Educational background & & & \\
No education & $1(2)$ & $5(8)$ & $6(10)$ \\
Primary & $27(43)$ & $20(32)$ & $47(74)$ \\
Middle/JHS/JSS* & $5(8)$ & $5(8)$ & $10(16)$ \\
Occupation & & & \\
Student/apprentice & $27(43)$ & $20(32)$ & $47(75)$ \\
Other & $6(10)$ & $10(16)$ & $16(15)$ \\
Household Size & & & $14(22)$ \\
$<5$ & $4(6)$ & $10(16)$ & $63(100)$ \\
5 and over & $29(46)$ & $20(31)$ & $49(77)$ \\
Number of Buruli Ulcer lesions & & & $55(87)$ \\
1 & $28(44)$ & $27(43)$ \\
2 and over & $5(8)$ & $3(5)$ & $8(13)$ \\
Total & $33(52)$ & $30(48)$ & \\
\hline
\end{tabular}

*JHS and JSS means Junior High School and Junior Secondary School respectively.

${ }^{\dagger}$ Other includes Muslim, Traditional and Other minor religions.

annual household cost was US\$570.09. The direct cost was $96 \%$ of the total cost. Non-medical cost accounts for about $97 \%$ of the direct cost with a mean cost of US $\$ 529.27$. The mean medical cost was US\$18.94. The main cost drivers of the household costs were transportation
(78\%) and food (12\%), with a mean cost of US\$444.71 and US $\$ 69.76$ respectively. For both children $(\mathrm{p}=0.11)$ and adults $(\mathrm{p}=0.89)$ there was no significant difference in household cost among the sexes. Table 4 provides the total and mean household economic costs.

Caregivers and adult patients lost a total of 535 productive days seeking care, which gives an indirect cost valued at US\$1,378.67 with a mean of US\$21.88. A total of 365 school days (about 1 year) were lost by 19 BU patients (mean, 19.2 days). Though most children were able to go to school after receiving treatment, about 33\% [15] of them reported late to school due to time spent seeking care at the facility. No BU caregiver was schooling. The household economic cost of BU treatment constituted about $45 \%$ of the household annual income.

\section{Intangible costs}

About $92 \%$ of BU patients felt some form of pain during the course of BU. Perceived pain and functional loss was low among respondents. Children felt more pain (mean, 1.0 and 0.3 for children and adults respectively) but had less functional loss compared to adults (mean, 0.8, 1.0 for children and adults respectively) as shown in Figure 2.

The mean response of both adult and children BU cases to stigma queries was 2.8. BU afflicted men were more likely to indicate that others think less of them $(\mathrm{p}=0.045)$. There was no difference between male and female responses to other queries on stigma, perception of pain or functional loss. About $84 \%$ of children were socially isolated, with $36 \%$ of these children never being accompanied for treatment. Those who were accompanied throughout their treatment were $11 \%$. The most cited reasons for this phenomenon were that the children could go by themselves and lack of money for transportation.

Table 4 Estimated total household economic cost of BU, Ghana, 2012

\begin{tabular}{|c|c|c|c|c|}
\hline \multirow[t]{2}{*}{ Direct costs } & \multicolumn{3}{|c|}{ Economic cost (US\$) } & \multirow[t]{2}{*}{ Cost profile (\%) } \\
\hline & Children $(n=45)$ & Adults $(n=18)$ & Total $(n=63)$ & \\
\hline \multicolumn{5}{|l|}{ Medical cost: } \\
\hline Wound dressing supplies (i.e., bandages, gauze, disinfectants, vaseline) & $504.32(11.21)^{\dagger}$ & $606.79(33.71)$ & $1,111.11(17.64)$ & 3.1 \\
\hline Other treatments (i.e., medication \& laboratory tests ): & $53.70(1.19)$ & $28.52(1.58)$ & $82.22(1.31)$ & 0.2 \\
\hline Sub-total: & $558.02(12.40)$ & $635.31(35.30)$ & $1,193.33(18.94)$ & 3.3 \\
\hline \multicolumn{5}{|l|}{ Non-medical cost: } \\
\hline Transportation & $18,866.67(419.26)$ & $9,150.33(508.35)$ & $28,017.00(444.71)$ & 78.1 \\
\hline Food (i.e., patient \& caregiver) & $3,094.63(68.77)$ & $1,300.00(72.22)$ & $4,394.63(69.76)$ & 12.2 \\
\hline Miscellaneous (i.e., soap, clothes, disinfectants, phone calls etc.) & $594.69(13.22)$ & $337.66(18.76)$ & $932.35(14.80)$ & 2.6 \\
\hline Sub-total: & $22,555.99(501.24)$ & $10,787.99(599.33)$ & $33,343.98(529.27)$ & 92.8 \\
\hline Total direct cost & 23,114.01 (513.64) & $11,423.30(634.63)$ & $34,537.31(548.21)$ & 96.2 \\
\hline Total valued indirect cost (i.e., productivity lost) & $332.98^{*}(7.40)$ & $1,045.69(58.09)$ & $1,378.67(21.88)$ & 3.8 \\
\hline Total cost (direct + indirect costs) & 23,446.99 (521.04) & $12,468.99(692.72)$ & $35,915.98(570.09)$ & 100 \\
\hline
\end{tabular}

*Caregivers associated cost not children.

${ }^{\dagger}$ Figures in parenthesis are means. 


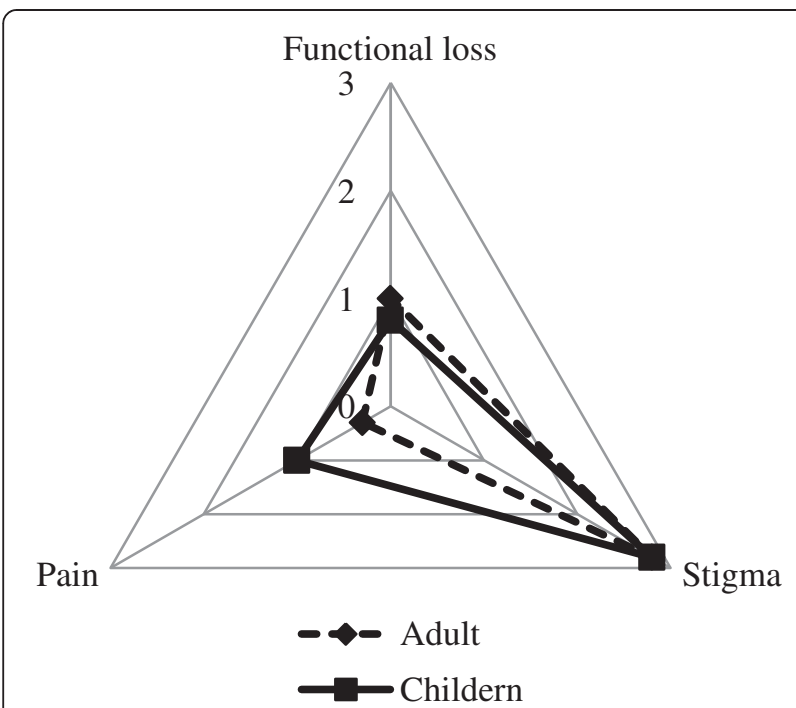

Figure 2 Mean responses of BU adults and children.

\section{Discussion}

The objective of this COIs study was to estimate household cost of BU in an endemic area. The distribution of age, sex and location of BU lesions among respondents is consistent with other BU studies $[4,6,10,13]$. The mean cost of BU treatment of US\$570.09 represents about 17\% of Ghana's 2012 Gross Domestic Product (GDP) per capita of $\$ 3,300^{\mathrm{a}}$ (PPP). The high direct cost reported is in keeping with previous studies on healthcare costs $[16,18]$. High contribution of non-medical direct costs mainly in the form of transportation was also found in Hong Kong and is explained by, the use of out-patient study participants who required daily transportation to the health facility for treatment [20]. We report lower food cost compared with that of other chronic illness like tuberculosis and Human Immunodeficiency Virus as BU patients do not typically require a special diet [16]. A lower direct cost of $\mathrm{BU}$ in a previous Ghanaian study is due to categorization of food and miscellaneous costs as indirect cost as compared to this study [6]. Low medical cost in our study stems from the free and short duration of treatments (median, 3 months) offered [6]. Other drivers of direct costs like co-morbidities and in-patient costs were not considered in this study [28].

High indirect cost of $\mathrm{BU}$ has been documented in Ghana and Cameroon among hospitalized patients whose caregivers rented accommodation, or regularly visited them $[6,15]$. We report lower indirect cost in this study because- our respondents were resident at home, most BU patients were students (75\%) whose productivity loss was not valued, most children were either never accompanied (36\%), or accompanied less than $50 \%$ of the times $(48 \%)$ to the $\mathrm{OHC}$ for treatment- their caregivers could therefore continue with their daily activities and hence incurred lower productivity losses (mean annual indirect cost, US\$7.04). Very high indirect cost (about $80 \%$ of total cost) documented among Swedish patients stems from the sole use of study participants in the productive age group in that study [21].

This study confirms that BU treatment poses significant burden on households forming a $45 \%$ economic burden. BU affected households are therefore likely to become impoverished. Despite the high cost burden of BU, affected households may be coping in the Ga South Municipality due to financial assistance with transportation and food costs from the NGO operating at the OHC. Communities that receive no such assistance are likely to develop coping mechanisms like sale of assets, borrowing of money and abandoning health facility based treatment documented in other studies [15,17]. Sensitivity analysis showed the estimated treatment costs were robust because varying assumptions and uncertainty causes a minimal $2.1 \%$ change in total BU costs.

School days lost by children in this study (mean of 19 days) is lower than reported in Cameroon [15]. The observed difference may be a consequence of choice of study participants - hospitalized patients who could obviously not be in school in the Cameroonian study, versus non-hospitalized patients who came for treatment and went to school afterwards in our study. Hospitalizations of $\mathrm{BU}$ patients suggest late presentation of $\mathrm{BU}$ requiring lengthier treatment and as such loss of more school days as compared with out-patient participants in this study. This implies that child BU patients in this study reported to the facility with early stages of BU. Such early reporting can be explained by intensification of health education and surveillance [29].

Buruli ulcer associated stigma is moderate among study participants (mean, 2.8 for both adults and children). Median scores for stigma among BU sufferers were computed using a four point Likert-like scale in an earlier study [24]. Acceptability of BU in this study community may be because stigma is reportedly low in highly endemic areas and where the cause of $\mathrm{BU}$ is not ascribed to magicoreligious beliefs [14,24]. A preference to keep others from knowing they have BU despite acceptability and sympathy for BU patients, and lack of significant difference in male and female response to stigmatizing behaviour we report, is consistent with an earlier finding [14]. High levels of discrimination of BU children among their peers reported earlier in Ghana was observed to be absent in this study an attitude change attributable to increasing levels of education about BU in schools in endemic areas [14,24].

Buruli ulcer is minimally painful when it presents as an oedematous lesion and this explains a general reporting of mild degree of pain in this study [4]. Functional limitation of BU patients in this study is described using a 5 point Likert scale which contained 19 items of the 
BUFLSQ. Previously reported BU related functional loss was done using a 3 point Likert-like scale and computing a functional loss that was a percentage of activities that a BU sufferer could no longer perform (as a result of BU) out of the 19 items of the BUFLSQ applicable to the BU sufferer $[22,23]$. The low functional limitation documented in this study is due to the selection of study participants who generally had less extensive lesions and therefore were seen on out-patient basis as compared to hospitalized patients who were likely to have more extensive lesions requiring surgery in the previous studies [22].

Most children (84\%) are socially isolated in this study. Social isolation as a coping mechanism for high BU cost of treatment was reported in Cameroon [15]. The higher rate of social isolation among children in this study as compared with the Cameroonian study (63\% of households isolated their BU household member) can be explained by not just high $\mathrm{BU}$ treatment cost but also by trust of caregivers in motorbike riders who are mostly locals of the communities contracted by the $\mathrm{OHC}$ and the operating NGO to transport all confirmed cases to the $\mathrm{OHC}$ and back. The social isolation of the children in this study may however, affect compliance with treatment as caregivers are not present to ensure compliance. This may in effect prolong treatment and further increase treatment costs.

\section{Limitations of the study}

The main limitation of this study is about the sample which is facility-based rather than population based and this can lead to selection bias. This data was however used because they were confirmed cases well documented and readily available. However, there is the likelihood of more unreported cases in the communities. Although intangible costs of BU like functional loss, social isolation, stigma and pain were measured, they were not valued in monetary terms as such an evaluation was beyond its scope.

\section{Conclusion}

This study has shown that despite free BU health facility based treatment; households incur substantial costs seeking BU care. For non-hospitalized BU patients, transportation cost can be enormous. Household cost of $\mathrm{BU}$ is therefore essential in the design of $\mathrm{BU}$ interventions. The total household cost of BU estimated in this study can therefore serve as a baseline cost for strategic planning and budgeting for future BU programmes, informing policy makers in the setting up of a financial framework on which future cost planning for $\mathrm{BU}$ will be based. An economic evaluation of BU should be undertaken with larger samples in other BU endemic areas to provide a trend and variability in cost of this debilitating disease to further inform policy on BU management.

\section{Endnote}

${ }^{a}$ http://www.indexmundi.com/ghana/economy_profile. html.

\section{Abbreviations}

BU: Buruli ulcer; BUFLSQ: Buruli Ulcer Functional Limitation Score

Questionnaire; CHPS: Community based Health Planning and Services;

COls: Cost-of-Illness study; OHC: Obom Health Centre.

\section{Competing interests}

The authors declare that they have no competing interests.

\section{Authors' contributions}

HBA participated in the design, undertook the data collection and participated in cost analysis. MA participated in the design and participated in cost analysis. All the authors were involved in drafting, revising the manuscript, reading and approving the final manuscript.

\section{Acknowledgements}

The authors are grateful to the Ga South Municipal Health Administration for collaborating with the study. Our special thanks also go to the staff of Obom Health Centre for their warm support, openness and willingness to provide data to us at all times. We also acknowledge the School of Public Health and the Noguchi Memorial Institute for Medical Research both of the University of Ghana, Legon for their technical support and also for the financial support from the Institute of Infectious Diseases of Poverty (IIDP), Dodowa Health Research Centre, Dodowa for their financial support in the conduct of this study. Finally, we sincerely thank all respondents for their co-operation and sharing of their personal information.

\section{Author details}

${ }^{1}$ Senior Medical Officer, Department of Civilian and Military Polyclinics, 37 Military Hospital, Accra, Ghana. ${ }^{2}$ Department of Health Policy, Planning \& Management, School of Public Health, College of Health Sciences, University of Ghana, P. O. Box LG13, Legon, Accra, Ghana.

Received: 13 May 2013 Accepted: 29 November 2013 Published: 5 December 2013

\section{References}

1. Ackumey MM, Kwakye-Maclean C, Ampadu EO, de Savigny D, Weiss MG: Health services for buruli ulcer: lessons from a field study in Ghana. PLOS Negl Trop Dis 2011, 5(6):e1187. doi:10.1371/journal.pntd.0001187.

2. Amofah G, Bonsu F, Tetteh C, Okrah J, Asamoa K, Asiedu K, Addy J: Buruli ulcer in Ghana: results of a national case search. Emerg Infect Dis 2002, 8(2):167-170. doi:10.3201/eid0802.010119.

3. World Health Organization: Report of the $7^{\text {th }}$ WHO advisory group meeting on Buruli ulcer. Geneva: WHO headquarters. [Internet]. 2012 Dec [cited 2012 Dec 10]. Available from: http://whqlibdoc.who.int/hq/2004/WHO_CDS_ CPE_GBUI_2004.9.pdf.

4. World Health Organization: Buruli ulcer disease. Fact sheet No 199. [Internet]. 2011 Dec [cited 2011 Dec 15]. Available from http://www.who.int/ mediacentre/factsheets/fs199/en/.

5. Aiga H, Amano T, Cairncross S, Domako JA, Ofosu-Kwabi N, Coleman S: Assessing water related risk factors for buruli ulcer: a case-control study in Ghana. Am J Trop Med Hyg 2004, 71(4):387-392.

6. Asiedu K, Etuaful S: Socioeconomic implications of buruli ulcer in Ghana: a three year review. Am J Trop Med Hyg 1998, 59(6):1015-1022.

7. Johnson PDR: Should antibiotics be given for buruli ulcer? Lancet 2010, 375(6736):10.

8. Portaels F, Elsen P, Guimaraes-Peres A, Fonteyne P, Meyers WM: Insects in the transmission of Mycobacterium ulcerans infection. Lancet 1999, 353:986.

9. Walsh DS, Portaels F, Meyers WM: Buruli ulcer (Mycobacterium ulcerans infection). Trans R Soc Trop Med Hyg 2008, 102:969-978. doi:10.1016/j. trstmh.2008.06.006

10. Hotez PJ, Kamath A: Neglected tropical diseases in Sub-Saharan Africa: review of their prevalence, distribution, and disease burden. Neg Trop Dis 2009, 3(8):e412. doi:10.1371/journal.pntd.0000412.

11. Nienhuis WA, Stienstra Y, Thompson WA, Awah PC, Abass KIM, Tuah W, Awua-Boateng NY, Ampadu EO, Siegmund V, Schouten JP, Adjei O, Brtetel G, 
van der werf TS: Antimicrobial treatment for early, limited Mycobacterium Ulcerans infection: A randomised controlled trial. Lancet 2010, 375(9715):664-672.

12. Johnson PDR, Stinear T, Small PLC, Plushke G, Merritt RW, Portaels F, Huygen K, Hayman JA, Asiedu K: Buruli ulcer (M. ulcerans infection): New insights, new hope for disease control. PLoS Medicine 2005, 2:282-286.

13. Amofah GK, Sagoe-Moses C, Adjei-Acquah C, Frimpong EH: Epidemiology of buruli ulcer in Amansie west district, Ghana. Trans R Soc Trop Med Hyg 1993, 87(6):644-645.

14. Renzaho AMN, Woods PV, Ackumey MM, Harvey SK, Kotin J: Communitybased study on knowledge, attitude and practice on the mode of transmission, prevention and treatment of Buruli ulcer in Ga West district, Ghana. Trop Med Int Health 2007, 12(3):445-458.

15. Grietens KP, Boock AU, Peeters H, Hausmann-Muela S, Toomer E, Ribera JM: "It is me who endures but my family that suffers": social isolation as a consequence of the household cost burden of buruli ulcer free of charge hospital treatment. PloS Neg Trop Dis 2008, 2(10):e321. doi:10.1371/journal. pntd.0000321.

16. Russell S: The economic burden of illness for households of developing countries: a review of studies focusing on malaria, tuberculosis and human immunodeficiency virus/ acquired immunodeficiency syndrome. Am J Trop Med Hyg 2004, 71(2):147-155.

17. Adamba C, Owusu YA: Burden of buruli ulcer: how affected households in a Ghanaian district cope. Afr Stud Monogr 2011, 32(1):1-23.

18. Casado V, Martinez-Yelanos S, Martinez-Yelamos A, Carmona O, Alonso L, Romero L, Moral E, Gubieras L, Arbizu T: Direct and indirect cost of multiple sclerosis in baix llobregat (Catalonia, Spain), according to disability. BMC Health Serv Res 2006, 6(143). doi:10.1186/1472-6963-6-143.

19. Minden K, Niewerth N, Listing J, Biedermann T, Schontube M, Zink A: Burden and cost of illness in patients with juvenile idiopathic arthritis. Ann Rheum Dis 2004, 63:836-842. doi:10.1136/ard.2003.008516.

20. Zhu TY, Tam L, Li EK: Societal cost of rheumatoid arthritis in Hong Kong: a prevalence based cost-of-illness study. Rheumatology 2011, 10(1093). doi:10.1093/rheumatology/ker014.

21. Virta L, Joranger P, Brox Jl, Eriksson R: Costs of shoulder pain and resource use in primary health care: a cost-of-illness study in Sweden. BMC Musculoskelet Disord 2012, 13(17). doi:10.1186/1471-2474-13-17.

22. Stienstra Y, Dijkstra PU, Guedenon A, Johnson RC, Ampadu EO, Mensah T, Klutse EY, Etuaful S, Deepak S, van der Graaf WTA, van der Werf JS: Development of a questionnaire assessing Buruli ulcer-induced functional limitation. Am J Trop Med Hyg 2004, 70(3):318-322.

23. Stienstra Y, Dijkstra PU, Van Wezel MJ, van Roest MHG, Beets M, Zijlstra I, Johnson RC, Ampadu EO, Gbovi J, Zinson C, Etuaful S, Klutse EY, van der Graaf WTA, van der Werf TS: Reliability and validity of Buruli ulcer functional limitation score questionnaire. Am J Trop Med Hyg 2005, 72(4):449-452.

24. Stienstra Y, Winette TA, van de Graaf, Asamoa K, van de Werf TS: Beliefs and attitudes towards Buruli ulcer in Ghana. Am J Trop Med Hyg 2002, 67(2):207-213.

25. Cochran WG: Sampling techniques. 2nd edition. New York: John Wiley and Sons, Inc:; 1963.

26. Johns R: Likert items and scales, Survey question bank: method fact sheet 1 . [Internet]. 2012 Jun [cited 2012 Jun 19]. Available from: http://surveynet.ac. uk/sqb/datacollection/likertfactsheet.pdf.

27. Hawker GA, Mian S, Kendzerska T, French M: Measures of adult pain. Arthiritis Care Res 2011, 63(11):240-252.

28. Le TK, Montejano LB, Cao Z, Zhao Y, Ang D: Healthcare cost in US patients with and without a diagnosis of osteoarthritis. J Pain Res 2012, 5:23-30. doi:10.2147/JPR.S27275.

29. Ackumey MM, Kwakye-Maclean C, Ampadu EO, de Savigny D, Weiss MG: Health Services for Buruli Ulcer Control: Lessons from a Field Study in Ghana. PLoS Neglected Tropical Diseases 2011, 5(6) doi:10.1371/journal. pntd.0001187.

doi:10.1186/1472-6963-13-507

Cite this article as: Amoakoh and Aikins: Household cost of out-patient treatment of Buruli ulcer in Ghana: a case study of Obom in Ga South Municipality. BMC Health Services Research 2013 13:507.

\section{Submit your next manuscript to BioMed Central and take full advantage of:}

- Convenient online submission

- Thorough peer review

- No space constraints or color figure charges

- Immediate publication on acceptance

- Inclusion in PubMed, CAS, Scopus and Google Scholar

- Research which is freely available for redistribution 